\title{
САМОПРЕЗЕНТАЦИЯ КАК ХАРАКТЕРИСТИКА СОЦИАЛЬНОГО ПОВЕДЕНИЯ СТАРШЕКЛАССНИКОВ
}

\section{??????????}

Тульский государственный педагогический университет им. Л.Н. Толстого, г. Тула, Тульская область,

Российская Федерация

В статье рассматриваются психологические особенности старшеклассников, определяюших стратегии самопрезентации в данном возрастном периоде. Для пониания поведенческих актов личности старшеклассника приводится классификация стратегий самопрезентации А. Шути. Предлагается авторская структурная модель самопрезентации старшеклассника.

Ключевые слова: старшеклассники; психологические особенности; самопрезентация; модель самопрезентации.

\section{SELF-PRESENTATION \\ AS A CHARACTERISTIC OF THE SOCIAL BEHAVIOR OF HIGH SCHOOL STUDENTS}

\section{Kulikova T.I.}

Tula State Lev Tolstoy Pedagogical University, Tula, Tula region, Russian Federation

The article deals with the psychological characteristics of senior pupils, who determine the strategies for self-presentation in a given age period. To understand the behavioral acts of senior pupils, the classification of self-presentation strategies by A. Schutz is given. The author's structural model of the self-presentation of the senior pupil is offered.

Keywords: senior pupils; psychological features; self-presentation; model of self-presentation. 
Понятие самопрезентация в переводе с английского обозначает «самоподача», то есть представление себя другим людям. По мнению Ж. Тедеши и М. Риеса, самопрезентация - это намеренное и осознаваемое поведение, направленное к тому, чтобы создать определённое впечатление у окружающих [4, с. 88].

Функция самопрезентации личности, как универсальная личностная способность, характерна для любого этапа онтогенеза. Однако способность к раскрытию и реализации собственных сущностных сил, жизненного опыта и потенциала наиболее актуальна в старшем школьном возрасте - важном этапе становления человека. Данный период характеризуется, прежде всего, возникновением нового уровня саморазвития личности, отличительной чертой которого является самораскрытие в межличностном общении через демонстрацию своих мыслей, характера и т.д. Это неосознаваемый процесс, он отражает социальную природу человека, его потребность в признании другими людьми. Его цель не только произвести впечатление, но и продемонстрировать то, что он из себя представляет [1]. Старшеклассники являются ещё недостаточно зрелыми и социально зрелыми людьми. Это личности, находящиеся на важной стадии формирования главных качеств, ещё недостаточно развиты, чтобы их можно было назвать взрослыми, но уже достаточно развиты, чтобы сознательно вступать в отношения с другими людьми и руководствоваться в своих действиях требованиями общественных норм. Главная отличительная черта старшеклассников - личностная нестабильность. В этот период противоположные черты и стремления сосуществуют и, в то же время, борются друг с другом, определяя тем самым противоречивость поведения подростка.

Совокупностью поведенческих актов личности, разделённых во времени и пространстве, направленных на создание определённого образа в глазах окружающих, является та или иная стратегия самопрезентации. Согласно А. Шутц, старшеклассники могут прибегать к любой из четырех групп стратегий самопрезентации [5, с. 611-628].

1. Позитивная самопрезентациия. Девиз: «Я хороший». Этот вид самопредъявления содержит активные, но не агрессивные действия по созданию позитивного впечатления о себе. К данной группе от- 
носятся такие стратегии: стремление нравиться, самопродвижение, служение примером.

2. Наступательная самопрезентащия. Основана на стремлении выглядеть хорошо, очерняя других людей. Это агрессивный способ создания желаемого образа, все тактики которого направлены на критику конкурента.

3. Предохранительная самопрезентация. Ставит перед собой цель не выглядеть плохо. Человек избегает возможности дать о себе негативное впечатление путем ухода от взаимодействия с другими людьми.

4. Оборонительная самопрезентащия. Субъект ведет себя активно в создании образа, но имеет установку на избегание негативного образа. Эта стратегия, как правило, разворачивается тогда, когда человека обвиняют в причастности к какому-то нежелательному событию. Чем более велика роль человека в этом событии, и чем оно тяжелее, тем труднее человеку изменить свой негативный образ в сторону позитивного.

Бурные социальные события, произошедшие за последние десятки лет в мире и в нашей стране, преобразования, продолжающиеся сейчас, собственной своей логикой вынуждают подрастающее поколение самостоятельно делать выбор, лично ориентироваться во всем и занимать вполне независимые позиции. Для старшеклассников характерно стремление применить свои возможности, проявить себя, что ведет к осознанию своей социальной приобщенности, именно в этот период стоит уделить особое внимание формированию навыков самопрезентации.

В старшем школьном возрасте основное место занимают потребности в развитии способностей, приобретении умений и отчетливо проявляется потребность к самореализации и соответственно в успешной самопрезентции [2]. Самопрезентация личности предполагает взаимодействие потребностей и способностей человека, где происходит развитие не только способностей, но потребностей, что обусловливается «родовой сущностью» человека и социальными отношениями. Развитие потребностей рассматривается в наиболее важном аспекте - потребности к продуктивной деятельности [3, 
с. 44 48]. У старшеклассника потребность в самореализации приобретает форму поиска своих возможностей, различных видов самопрезентации. Здесь идет речь о внешней самореализации, которая соседствует со стремлением к реализации сущностной и приобретает форму нахождения себя в учебно-профессиональной деятельности. При наличии этого стремления повышается сознательность ученика в усвоении знаний, меняется отношение к учебной деятельности, появляется способность к достижению цели без посторонней помощи, к автономному поведению и творческой активности. Хотя эта взаимозависимость не у всех школьников имеет одинаковый характер.

По мнению ряда исследователей (С.Л. Рубинштейн, А. Маслоу, К. Роджерс и др.), потребность в самореализации личности потенциально существует у всех учащихся, но не всякая деятельность, организованная учителем, мотивирует учащихся в реализации своих возможностей. Именно в старшем школьном возрасте мотивы учения связаны, прежде всего, с их будущей позицией в жизни и с предстоящей профессиональной деятельностью. Старшеклассники обращены в будущее. Все настоящее, потребности, в том числе и учение, выступает для них мотивационным центром, который определяет их деятельность, поведение, отношение к окружающему миру, стремление к самореализации.

На основе анализа философской, психологической и педагогической литературы по проблеме самопрезентации личности, мы приходим к пониманию функции самопрезентации личности как универсальной личностной способности к выявлению, раскрытию и опредмечиванию своих сущностных сил. Функция самопрезентации личности старшеклассников - как универсальная личностная способность - обладает сущностными качественными характеристиками, каковыми являются:

- самостоятельность как универсальная способность к планированию, регулированию, целенаправленности своей деятельности, к рефлексии себя и других;

- свобода как универсальная способность личности к автономному поведению (свободе выбора, действия, решения), саморегуляции, воле и межличностному взаимодействию; 
- творчество как универсальная способность к концентрации творческих усилий, креативности в деятельности, независимости в суждениях и ответственности за свои действия и поступки.

На основе теоретического анализа научной литературы можно представить структурную модель самопрезентации старшеклассника (рис. 1).

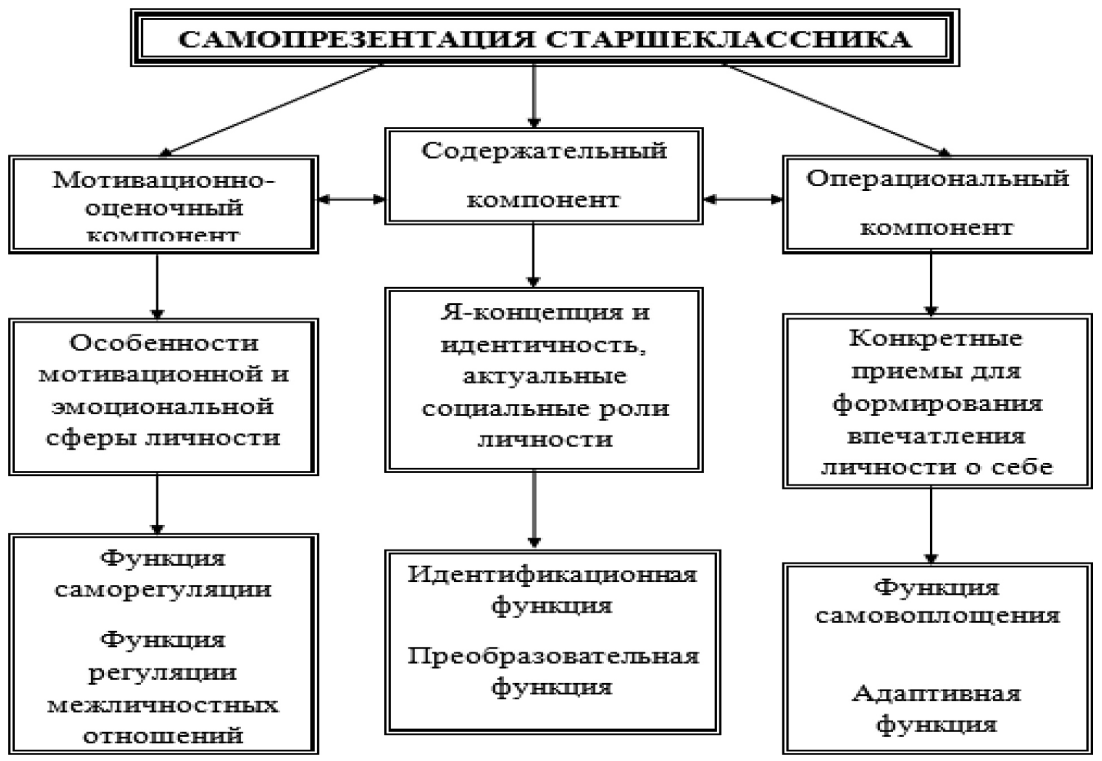

Рис. 1. Структурная модель самопрезентации старшеклассника

Предложенная структурная модель самопрезентации старшеклассника включает три основных компонента: мотивационно-оценочный, содержательный и операциональный.

Развитие самопрезентации личности имеет свою логику, этапы, уровни. Мы представляем процесс ее развития в определенной динамике: от низкого уровня развития, менее совершенного, к среднему и высокому - более совершенному. Высокий уровень развития самопрезентации представлен сформированностью трех компонентов данной структурной модели. 
Независимо от того, является ли самопрезентация стихийной или регулируемой, она формирует у старшеклассника конкретный уровень ожиданий и стиль взаимоотношений, она является способом взаимодействия на окружение. Самопрезентация - это процесс предъявления собственного образа, межличностное взаимодействие, важной особенностью которого является умение «принимать роль другого человека», представлять, как воспринимают его окружающие и, соответственно, конструировать свои действия.

\section{Список литературы}

1. Кон И.С. Психология ранней юности / И. С. Кон. - М.: Вако, 2003.

2. Кулагина И.Ю. Возрастная психология (Развитие ребенка от рождения до 17 лет): Учебное пособие. 5-е изд. / И.Ю. Кулагина. М.: Изд-воУРАО, 1999.

3. Медведева И.А. Самопрезентация - моделирование личности / И.А. Медведева // Материалы Международной научно-практической конференции молодых ученых «Психология XXI века». Под науч. ред. О.Ю. Щелковой. СПб.: Изд-во С.-Петерб. ун-та, 2010.

4. Шепель В.М. Имиджелогия. Как нравиться другим людям / В.М. Шепель. М., 2002.

5. Schutz A. Assertive, offensive, protective, and defensive styles of selfpresentation: a taxonomy // The Journal of psychology, 132 (6), 1998.

\section{References}

1. Kon I.S. Psikhologiya ranney yunosti / I.S. Kon. M.: Vako, 2003.

2. Kulagina I.Yu. Vozrastnaya psikhologiya (Razvitie rebenka ot rozhdeniya do 17 let): Uchebnoe posobie. 5-e izd. / I.Yu. Kulagina. M.: Izd-voURAO, 1999.

3. Medvedeva I.A. Samoprezentatsiya - modelirovanie lichnosti / I.A. Medvedeva // Materialy Mezhdunarodnoy nauchno-prakticheskoy konferentsii molodykh uchenykh «Psikhologiya XXI veka». Pod nauch. red. O.Yu. Shchelkovoy. SPb.: Izd-vo S.-Peterb. un-ta, 2010.

4. Shepel' V.M. Imidzhelogiya. Kak nravit'sya drugim lyudyam / V.M. Shepel'. M., 2002.

5. Schutz A. Assertive, offensive, protective, and defensive styles of selfpresentation: a taxonomy // The Journal of psychology, 132 (6), 1998. 